\title{
Effects of Reed Rootstocks on Hydraulic Properties of Surface Soil in the Shuangtai Estuary Wetland, Northeast China
}

\author{
Qian Lin ${ }^{1}$, Tadaharu Ishikawa ${ }^{1}$, Ryosuke $\mathrm{Akoh}^{1}$, Fenglin Yang ${ }^{2}$ and Shushen Zhang ${ }^{2}$ \\ 1. Department of Environmental Science and Technology, Tokyo Institute of Technology, Yokohama 226-8502, Japan \\ 2. School of Environmental and Biological Science, Dalian University of Technology, Dalian 116024, China
}

\begin{abstract}
A set of field experiments was conducted to investigate the effects of reed rootstocks on hydraulic properties of surface soils in the Shuangtai Estuary Wetland, Northeast China. The soil particle size distribution and rootstock content were analyzed, and the vertical soil water profile was monitored by using a multisensory capacitance system. Hydraulic conductivity of the surface soil layer was estimated by in si-tu infiltration. The soil was silt loam with less sand; soil texture was consistent though the vertical profile, but bulk density was lower in the upper $20 \mathrm{~cm}$, where the fine roots were concentrated. The surface soil moisture profile changed dynamically, and variation in vertically integrated soil moisture was consistent with observed precipitation and estimated evaporation. Infiltration capacity was $30 \mathrm{~cm} \cdot \mathrm{d}^{-1}$, much larger than typical hydraulic conductivity values for silt loam with less sand. These findings suggest that fine annual roots change the soil matrix and hydraulic conductivity in surface soils. A vertical one-dimensional water transport model was presented based on Richard's equation. Model parameters were estimated from the soil analyses and literature data. The computation accurately reproduced the dynamic changes in moisture in surface soils containing large volumes of fine rootstock.
\end{abstract}

Key words: Soil moisture, reed colony, water conductivity, field measurement, 1-D (one-dimensional) numerical simulation.

\section{Introduction}

Expansive and rich wetland ecosystems often form on alluvial deltas because of water retention and deposition of fine sediments that contain organic matters and nutrients. Perennial emergent plant species, such as reed (Phragmitesaustralis), are the dominant biota in alluvial wetlands and serves as the base of biomass production and wildlife habitat [1]. High rates of water uptake by emergent vegetation control water transport across and below the ground surface. Field observations indicate that evapotranspiration from reed colonies is $3-8 \mathrm{~mm} \cdot \mathrm{d}^{-1}$ during the growing season [2-4], usually comparable to or larger than average seasonal precipitation.

Rootstocks of perennial plants that colonize the

Corresponding author: Tadaharu Ishikawa, professor, Ph.D., research fields: environmental hydraulics and hydrology. E-mail: ishikawa.t.ai@m.titech.ac.jp. surface soil matrix can change soil properties and water conductivity and affect shallow groundwater movement and material transport. It is well known that plant rootstocks in croplands affect porosity and water permeability of surface soils [5-8]. However, the influence of rootstocks on movement of soil water in wetlands has not been investigated in details.

In this paper, the effects of rootstocks on hydraulic properties of surface soil are assessed using field measurements performed in reed colonies in Shuangtai Estuary Wetland, National Nature Reserve in Northeast China. Rootstock content and soil texture were analyzed by depth and the vertical soil water profile was monitored continuously using a multisensory capacitance system. Hydraulic conductivity of surface soil was estimated by in si-tu infiltration. A 1-D (one-dimensional) water transport model that estimates soil moisture changes in the reed 
colony was presented based on Richard's equation.

\section{Methods}

\subsection{Field Measurements}

\subsubsection{Study Site}

Shuangtai Estuary Wetland covers 223,000 ha in Liaohe Delta, Northeast China $\left(40^{\circ} 45^{\prime}-41^{\circ} 10^{\prime} \mathrm{N}\right.$, $\left.121^{\circ} 30^{\prime}-122^{\circ} 00^{\prime} \mathrm{E}\right)$. Because it contains a colony of the protected plant Suaedaheteroptera and habitat for the red-crowned crane (Grusjaponensis) and Saunder's Gull (Larussaundersi), the wetland was nominated for designation as a National Nature Reserve of China in 1985. The wetland also included one of the world's largest reed colonies (approximately 83,000 ha), which supplies material for the local paper industry. To prevent negative effects of ground salinity on reed quality, the reed area is irrigated with water from the Shaungtai River and Raoyang River. The study area and sampling locations are shown in Fig. 1.

Air temperature in the study region is $<0{ }^{\circ} \mathrm{C}$ from late November through early March, and surface soils generally remain frozen until April (Fig. 2). The reed area is irrigated in April to melt the surface soil, but the primary irrigation season occurs from May through mid-August. After the irrigation water is drained, the reed area experiences natural evaporation and precipitation until the end of November. Reeds are harvested just after the surface soil freezes. Figs. $3 \mathrm{a}$ and $3 \mathrm{~b}$ show the reed colony at the measurement site 2 weeks after the beginning of irrigation (May) and prior to harvesting (October), respectively. The field experiment was conducted in September and October, 2011.

\subsubsection{Data Collection}

Monitoring instruments were set up on May 7, 2011 prior to the primary irrigation, and measurements continued until October 26. A pressure gauge with built-in memory was positioned $3.5 \mathrm{~cm}$ above the ground surface to record the standing water level. Another pressure gauge was located $170 \mathrm{~cm}$ below the

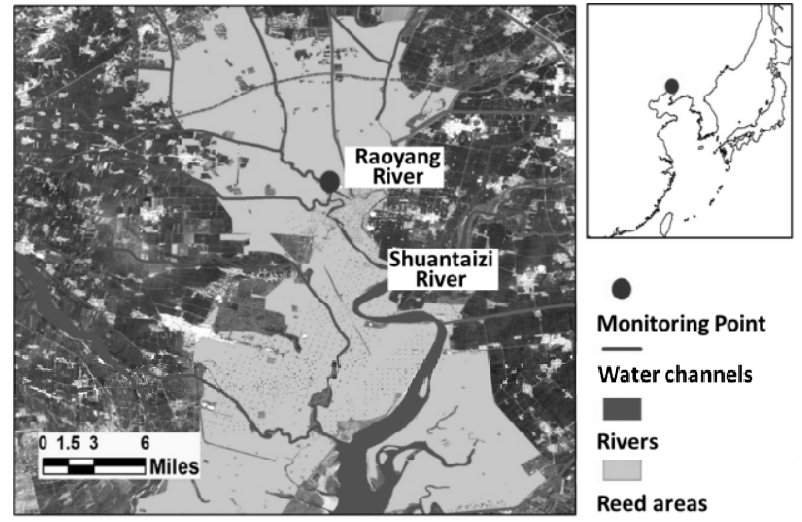

Fig. 1 Map of the study location.

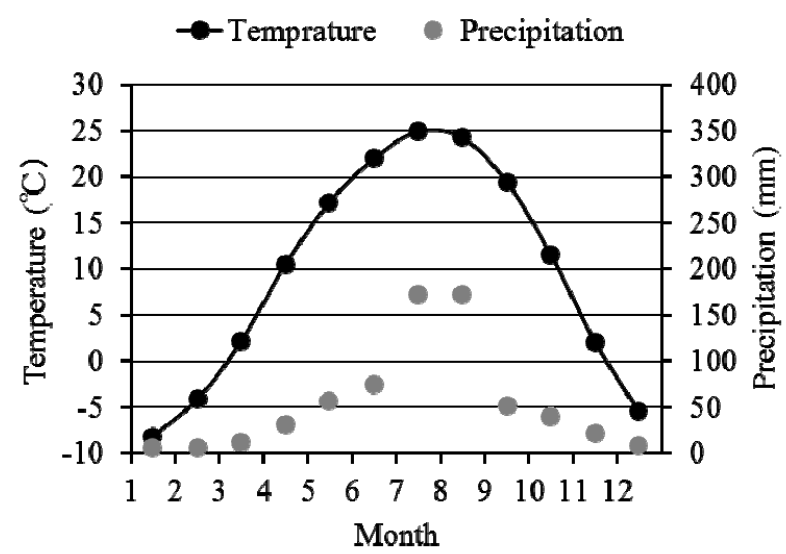

Fig. 2 Temperature and precipitation at the study site.

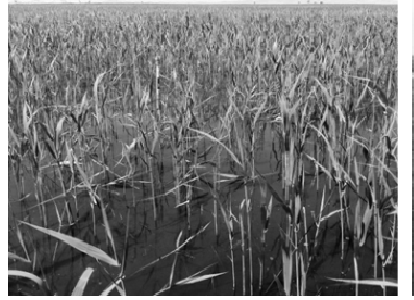

(a)

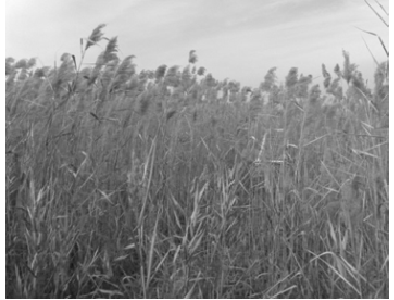

(b)
Fig. 3 Condition of the reed colony.

ground surface in a vertical plastic access tube (56.5-mm in dia.) to measure the groundwater level (Fig. 4). Atmospheric pressure variability was corrected using output from additional pressure gauge located nearby on dry land.

The vertical soil moisture profile was monitored using a multisensory capacitance system (TriSCAN, Sentic Ltd.) that measured the relative capacity of static electricity of surrounding soil, and $S F$ (specific frequency) was defined as in Eq. (1): 


$$
S F=\left(F_{a}-F_{s}\right) /\left(F_{a}-F_{w}\right)
$$

where, $F_{a}, F_{s}$ and $F_{w}$ are frequency readings of the sensor in air, soil, and water, respectively. Eight sensors were placed in a vertical access tube (56.5-mm dia.) at the depths shown in Fig. 4.

After removing the equipment on October 26, soil samples were collected in $10-\mathrm{cm}$ layers from the ground surface to $60 \mathrm{~cm}$ for analysis of rootstock content, and four soil cores for soil property analysis were sampled horizontally using a 5-cm metal pipe.

Water infiltration rate was measured to estimate hydraulic conductivity of the surface soil layer on October 28, when the groundwater table was $17 \mathrm{~cm}$ below the surface. A plastic cylinder $(40 \mathrm{~cm}$ dia. $\times 30$ $\mathrm{cm}$ tall) was pushed into the ground vertically to 10 $\mathrm{cm}$. After sudden water loading in the cylinder, the velocity of water surface falling was measured.

2.1.3 Calibration of Multisensory Capacitance System

Correlation between $S F$ and soil water content $\theta$ was tested in the laboratory and at the study site. The laboratory experiment was conducted in a plastic cylinder (36 cm-dia., $30 \mathrm{~cm}$ high) using the soil collected from the $0-20 \mathrm{~cm}$ and $20-40 \mathrm{~cm}$ layers. After removing rootstocks, the soil was washed, dried, added water to some content and placed in the column. The access tube (56.5 mm-dia.) containing one sensor was set at the center of the cylinder. After measurement of $S F$, soil samples were collected near the sensor to determine the water content and bulk

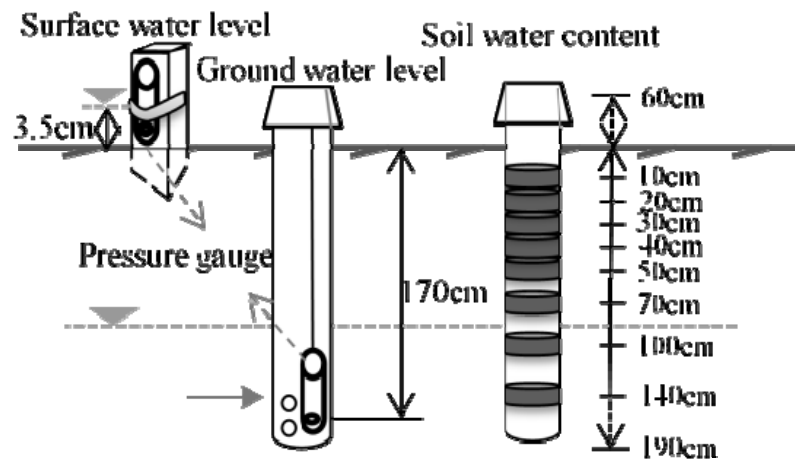

Fig. 4 Schematic description of field instrumentation. density. This process was repeated 7 times to cover a wide range of water content. Bulk density was almost constant $\left(1.13 \pm 0.03 \mathrm{~g} \cdot \mathrm{cm}^{-3}\right)$. Field tests were conducted on October 8 and October 27, when the soil was unsaturated. Soil cores were sampled from the 10, 20,30 and $50-\mathrm{cm}$ layers, $3 \mathrm{~m}$ from the $S F$ probe, to measure $\theta$ at each depth.

Because the groundwater of the Shuangtai Estuary Wetland contains some salinity, the response of $S F$ to salinity was tested in the laboratory under saturated soil conditions using $\mathrm{NaCl}$ solution. After measuring $S F$, salinity of the soil samples was measured as electrical conductivity $\left(E C_{1: 5} \quad \mathrm{~s} \cdot \mathrm{m}^{-1}\right)$ using a $1: 5$ soil-to-water extract [9].

\subsubsection{Numerical Simulation}

Richard's equation was used to simulate vertical water flow in the soil:

$$
\frac{\partial}{\partial z}\left\{K(\theta) \frac{\partial}{\partial z}(h+z)\right\}=\frac{\partial \theta}{\partial t}=C(\theta) \frac{\partial h}{\partial t}
$$

where, $K(\theta)$ is hydraulic conductivity, $h$ is water pressure head, $z$ is the vertical coordinate (positive upward), $t$ is time, and $C(\theta)$ is specific capacity. The van Genuchten's function was adopted for $K(\theta)$ [10]:

$$
K(\theta)=K_{s} \cdot S_{e w^{2}} \frac{1}{2}\left\{1-\left(1-S_{e w^{m}}\right)^{m}\right\}^{2}
$$

where, $S_{e w}$ is effective saturation normalized by saturated and residual water content $\left(\theta_{s}\right.$ and $\theta_{r}$, respectively), as given in Eq. (4):

$$
S_{e w}=\frac{\theta-\theta_{r}}{\theta_{s}-\theta_{r}}=\frac{1}{\left(1+|\alpha h|^{n}\right)^{n}}
$$

Where $\alpha$ and $n$ are empirical constants, and $m=1-$ $1 / n$. The expression of $C(\theta)$ is obtained from Eq. (5):

$$
C(\theta)=\frac{\alpha m n\left(\theta_{s}-\theta_{r}\right)|\alpha h|^{n-1}}{\left(1+|\alpha h|^{n}\right)^{m+1}}
$$

\section{Results and Discussion}

\subsection{Records of Hydraulic Condition}

Daily precipitation, surface water level, and 
groundwater table values are presented in Fig. 5. Irrigation began on May 12. Drainage began on August 16; the soil surface was dry on August 25 but was inundated again after rainfall that occurred from August 27 to 31 . The groundwater table fell after September 5 , but rose to the surface again after a 38-mm rainfall on October 13-14.

The $S F$ records according to depth are shown in Fig. 6. $S F$ was nearly constant at each depth during the irrigation period when the soil was saturated. $S F$ began to decrease and fluctuate slightly with rainfalls in early September. The range of variation in $S F$ was larger in shallower than in deeper soil layers.

\subsection{Soil Properties and Rootstock Distribution}

The proportions of sand, silt, and clay were consistent

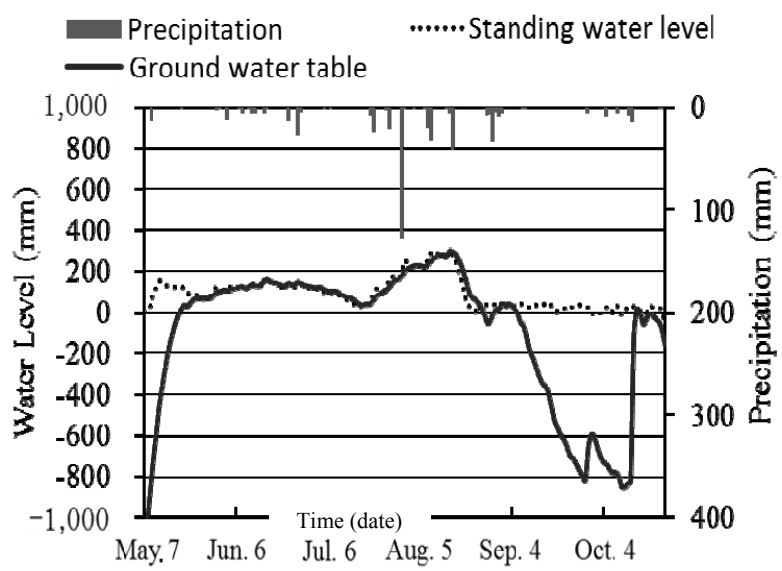

Fig. 5 Daily precipitation and water level.

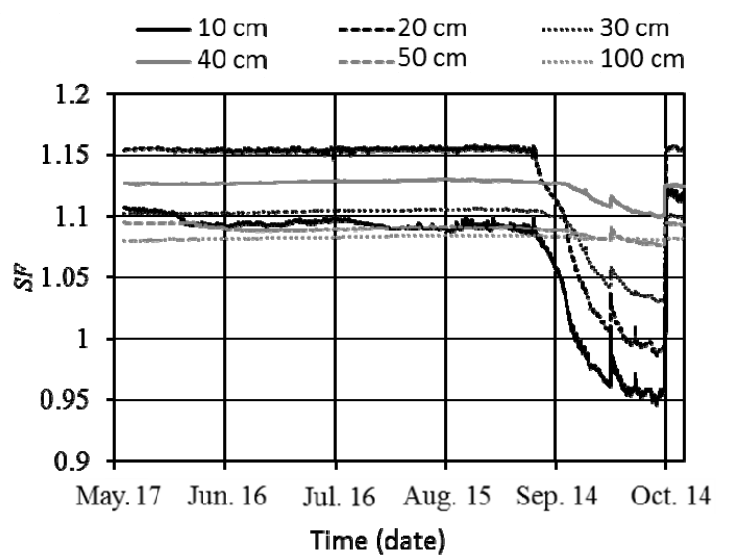

Fig. 6 Relative capacity of static electricity, SF. with depth, and the soil was classified as "silt loam with less sand". Bulk density increased with depth, while soil particle density was constant, which reflected the greater porosity near the ground surface.

An image of the rootstocks obtained from the $0-10$ $\mathrm{cm}$ layer is provided in Fig. 7. Root material was classified into three categories by appearance: UGS (underground stems), FOR (first-order roots), and SOR (second-order roots). FOR were roots that diverged from UGS, and SOR were thin roots that branched from FOR. SOR penetrate into openings among soil grains. UGS are approximately $7-15 \mathrm{~mm}$ thick, while the typical diameter of SOR is approximately $0.3 \mathrm{~mm}$.

Fig. 8 shows the density distribution of rootstocks. UGS were distributed throughout the sampled profile and occupied the largest mass. FOR were also distributed throughout the layer, but represented a small proportion of root mass. SOR were concentrated in the upper $20 \mathrm{~cm}$ and comprised approximately half the mass of UGS. From the difference of diameters, the total surface area and length of SOR were estimated approximately 20 -fold and 500-fold larger, respectively, than those of UGS, suggesting that SOR might have a stronger effect than UGS on surface soil properties.

Table 1 Soil properties.

\begin{tabular}{|c|c|c|c|c|c|}
\hline \multirow{2}{*}{$\begin{array}{l}\text { Depth } \\
\text { (cm) }\end{array}$} & \multirow{2}{*}{$\begin{array}{l}\text { Bulk density } \\
\left(\mathrm{g} \cdot \mathrm{cm}^{-3}\right)\end{array}$} & \multicolumn{3}{|c|}{ Proportion $(\%)$} & \multirow{2}{*}{ Porosity } \\
\hline & & Sand & Silt & Clay & \\
\hline 10 & 1.05 & 7.5 & 75.8 & 16.7 & 0.59 \\
\hline 20 & 1.17 & 3.5 & 78.2 & 18.3 & 0.55 \\
\hline 30 & 1.25 & 9.4 & 74.3 & 16.3 & 0.52 \\
\hline 50 & 1.29 & 6.0 & 79.7 & 14.3 & 0.52 \\
\hline
\end{tabular}

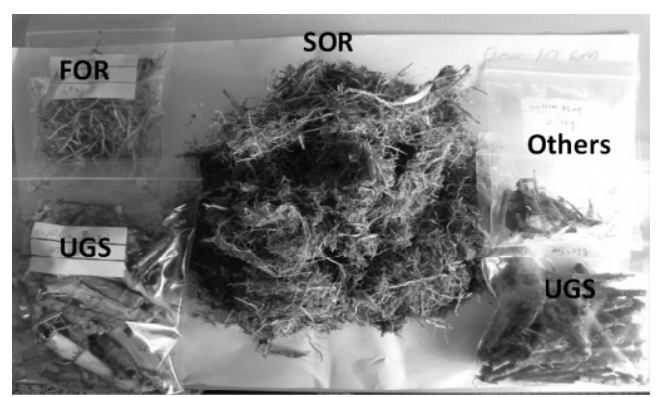

Fig. 7 Classification of reed rootstocks. 


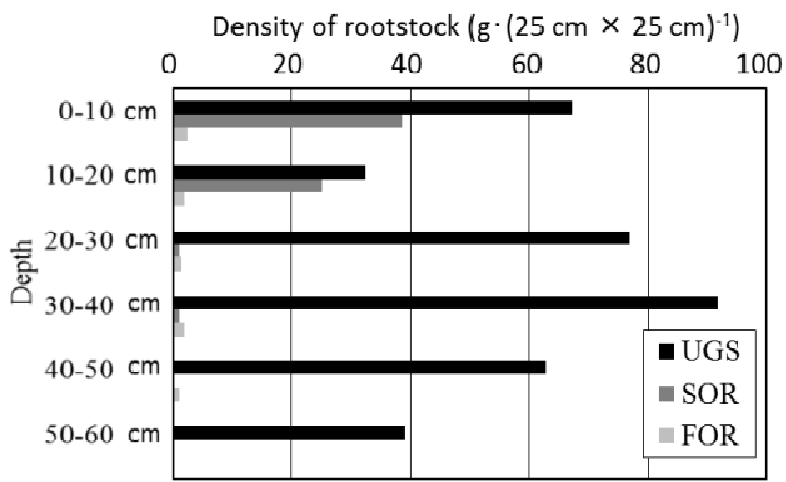

Fig. 8 Vertical distribution rootstocks.

\subsection{Hydraulic Conductivity in the Surface Soil Layer}

Sudden loading of surface water on a soil layer that is in hydrostatic equilibrium will cause downward propagation of a saturation front. Piezometric head $h$ is approximately constant in the saturated layer above the front. Eqs. (6) and (7) are obtained by integrating Eq. (2) from a point just under the front to the ground surface [11]:

$$
\begin{gathered}
\frac{\partial K(\theta)}{\partial z}=\frac{\partial \theta}{\partial t} \\
K_{s}-K_{f}=\int \frac{\partial \theta}{\partial t} d z=\frac{\partial V}{\partial t}
\end{gathered}
$$

where, $V$ is total water content above the front, $K_{s}$ is saturated hydraulic conductivity at the ground surface, and $K_{f}$ is unsaturated conductivity below the front. Because $K_{f}<<K_{s}, K_{s}$ can be approximated with the increase rate in $V$ if evaporation is negligible. The water surface level record (Fig. 9) shows that $K_{s}$ of surface soils that are high in SORare approximately $30 \mathrm{~cm} \cdot \mathrm{d}^{-1}$. This value is much larger than $K_{s}$ value for silty loam found in Ref. [12].

\subsection{Calibration of Multisensory Capacitance System}

The dependence of $S F$ on $E C_{1: 5}$ under saturated conditions, revealed in laboratory and field data, isillustrated in Fig. 10. These results suggest that salinity has a negligible effect on $S F$.

The correlation between $S F$ and soil water content is often expressed as Eq. (8):

$$
\theta=a \times S F^{b}+c
$$

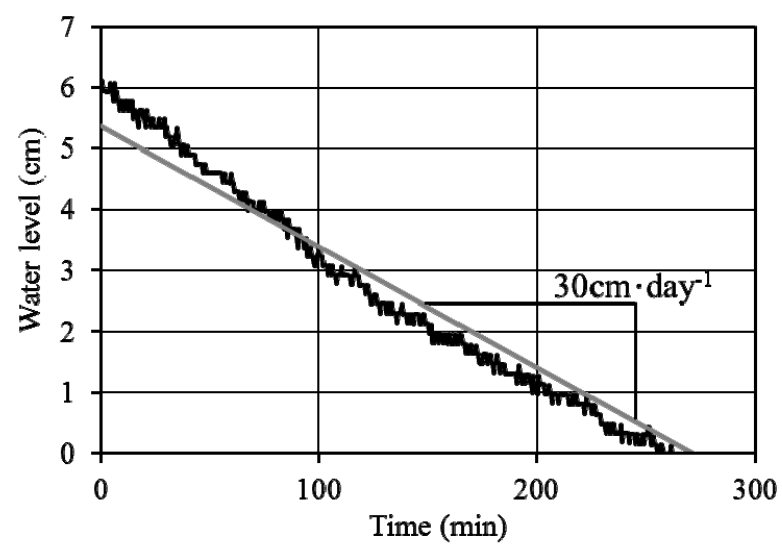

Fig. 9 Infiltration rate after sudden loading.

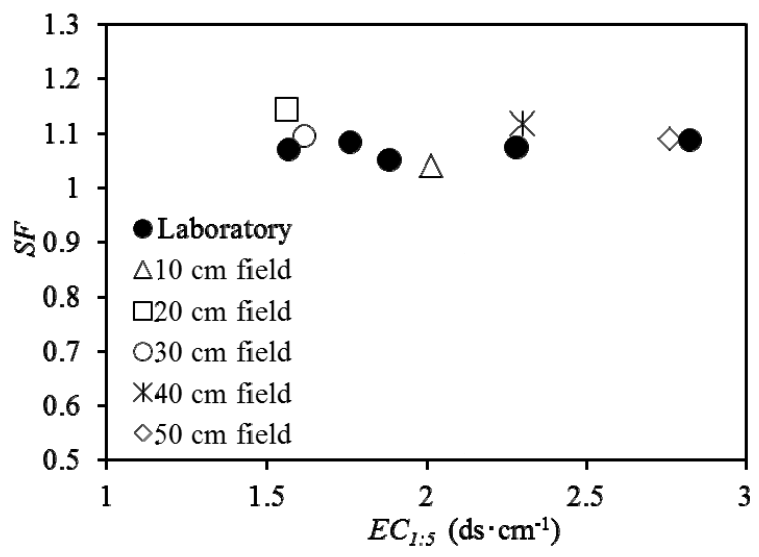

Fig. 10 Dependency of $S F$ on $E C_{1: 5}$ (saturated condition).

where, $\theta$ is volumetric water content (\%), and $a, b$ and $c$ are fitting coefficients. Field and laboratory experiments show that the relationship between $S F$ and $\theta$ depends on soil type and degree of compaction [13-14].The results of calibration between laboratory and field data are plotted in Fig. 11.

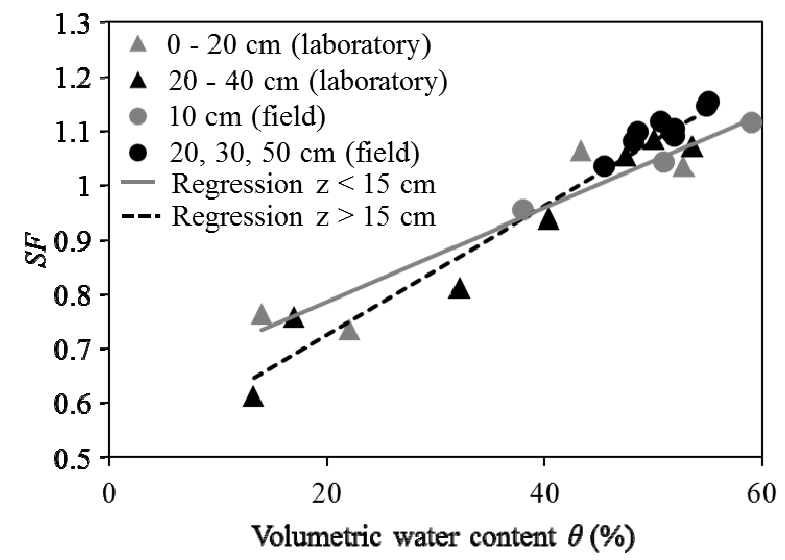

Fig. 11 Dependency of $S F$ on volumetric water content for unsaturated condition. 
The regression lines in Fig. 11 are expressed as Eq. (9):

$$
\begin{array}{ll}
z<15 \mathrm{~cm} & \theta=0.0086 \times S F+0.61 \\
z>15 \mathrm{~cm} & \theta=0.0118 \times S F+0.49
\end{array}
$$

Fig. 12 shows the time series of $\theta$ at each depth obtained from Eq. (9); vertical profiles constructed from the same data are shown in Fig. 13. The at $10 \mathrm{~cm}$ after the rainfall on October 13 exceeded the value during the irrigation term, which suggests that the surface soil layer had expanded during the drying period.

Soil water content was variable in the top layer, where SOR caused increased porosity and saturated hydraulic conductivity (Table 1 and Fig. 8). These results suggest that reed rootstocks have a strong influence on vertical water transport.

\subsection{Numerical Simulation}

\subsubsection{Model Parameters}

Model parameters were determined for three soil layers (Table 2) based on Ref. [12] and the results of soil analyses in the present study. For deeper layers $(z$ $<-25 \mathrm{~cm}$ ), typical literature values for silt were adopted, except for $\theta_{s}$, which should be equal to the porosity obtained by soil analysis (Table 1 ). The $\theta_{s}$ values for the shallow layer containing SOR $(z>-15$ $\mathrm{cm} ; 15 \mathrm{~cm}<z<-25 \mathrm{~cm}$ ) were also assumed to be equal to the porosity. The values of $\theta_{r}$ were assumed to be typical for silt, because no data were available to determine actual $\theta_{r}$ values. The value of $K_{s}$ assumed for the top two layers was $30 \mathrm{~cm} \cdot \mathrm{d}^{-1}$, as obtained by the infiltration test. The $\alpha$ and $n$ for the top two layers were determined based on the dependence of $\alpha$ and $n$ on $K_{s}$, and the linear correlation between $\alpha$ and $n$ obtained from Ref. [12] (Figs. 14 and 15). From these data, the values of $\alpha=0.025$ and $n=1.44$ (horizontal dotted lines in Fig. 14) were selected.

\subsubsection{Computation and Discussion}

Water content in the soil column of $2 \mathrm{~m}$ deep was calculated from September 4 to October 14 when the groundwater table was changing. Saturation condition

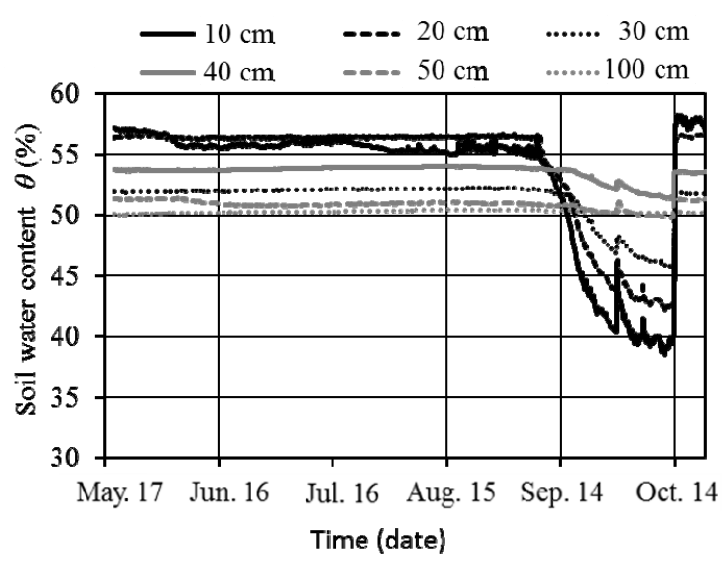

Fig. 12 Time series of water content.

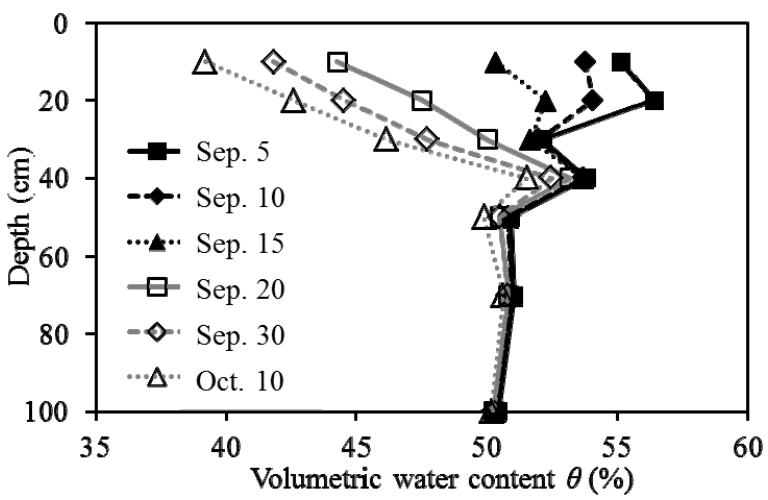

Fig. 13 Profiles of water content at 5-d intervals.

Table 2 Hydraulic properties for numerical simulation.

\begin{tabular}{llllll}
\hline $\mathrm{z}(\mathrm{cm})$ & $\theta_{r}$ & $\theta_{s}$ & $\begin{array}{l}\alpha \\
\left(1 \cdot \mathrm{cm}^{-1}\right)\end{array}$ & $n$ & $K_{s}\left(\mathrm{~cm} \cdot \mathrm{d}^{-1}\right)$ \\
\hline $0-15$ & 0.03 & 0.56 & 0.025 & 1.44 & 30 \\
$15-25$ & 0.03 & 0.55 & 0.025 & 1.44 & 30 \\
$>25$ & 0.03 & 0.52 & 0.016 & 1.37 & 6 \\
\hline
\end{tabular}

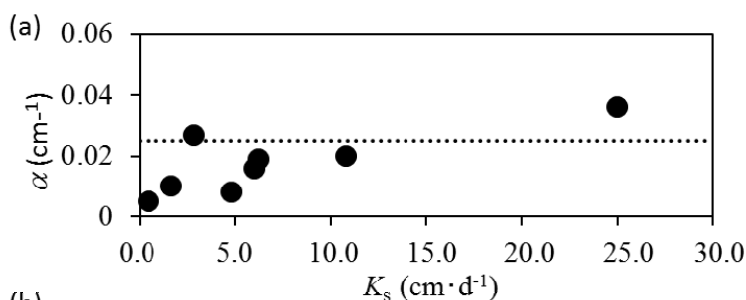

(b)

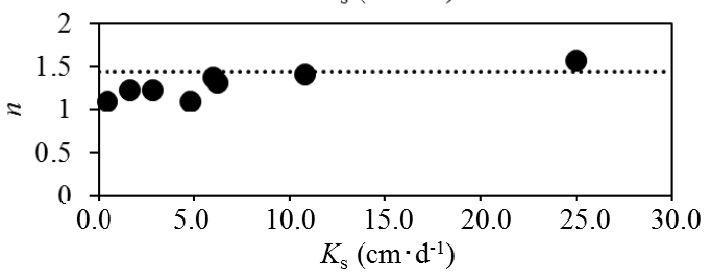

Fig. 14 Dependency of parameters on $K_{\mathrm{s}}:$ (a) $\alpha$, (b) $n$. 


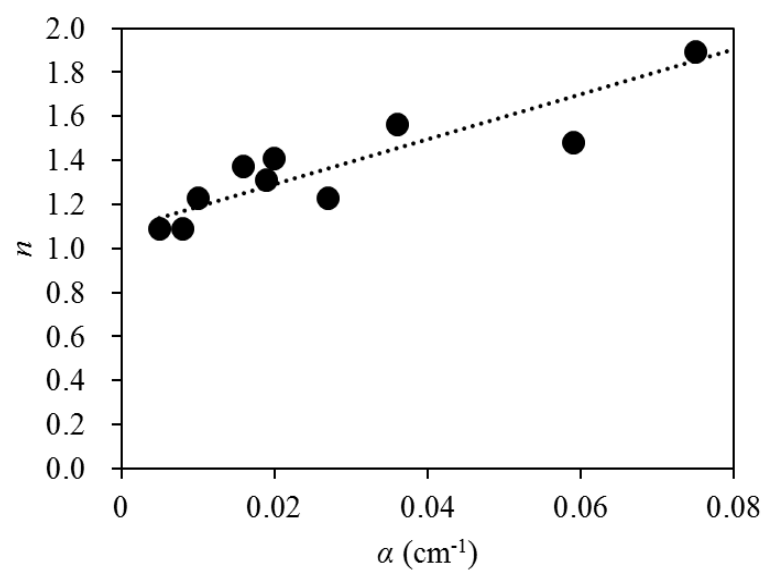

Fig. 15 Correlation between $\alpha$ and $n$.

was given at the depth of groundwater table shown in Fig. 15. The finite control volume method was applied to Richard's equation with a grid size of $0.5 \mathrm{~cm}$ and time increment of $10 \mathrm{~s}$.

Inflow at the ground surface was given by average daily rainfall. However, when rainfall exceeded $K_{s}=$ $30 \mathrm{~cm} \cdot \mathrm{d}^{-1}$, inflow was assumed to be equal to $K_{s} . E T$ (evapotranspiration) was counted only for days without rain, using Eq. (10) [15]:

$$
\text { ETsoil }=\left(1-\sigma_{f}\right) \frac{\theta}{\theta_{s}} \cdot E T
$$

where, $\sigma_{f}$ is an empirical constant obtained from the normalized difference vegetation index. In this study, $\sigma_{f}=0.6$ was selected by referring to a global image of vegetation index [16].

Figs. 16 (a) and 16 (b) compare the simulation results and observational data. The calculations reproduced fluctuations in soil moisture fairly well, although the calculated results were limited by discontinuities of parameter values shown in Table 2 . This suggests that Richard's equation is applicable for estimating vertical water transport in surface soils that contain a large volume of fine rootstocks, by appropriate calibration of hydraulic parameters.

\section{Conclusions}

The effect of reed rootstocks on soil hydraulic properties was examined through field experiments in Shuangtai Estuary Wetland in autumn, 2011. Major (a) $10 \mathrm{~cm} 20 \mathrm{~cm} 30 \mathrm{~cm} 40 \mathrm{~cm} 50 \mathrm{~cm} 100 \mathrm{~cm}$

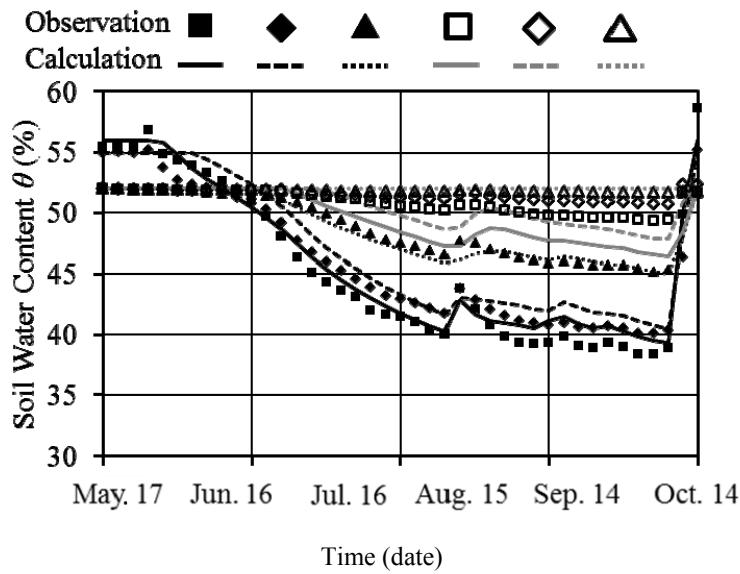

(b) Sep. 5 Sep. 10 Sep. 15 Sep. 20 Sep. 30 Oct. 10

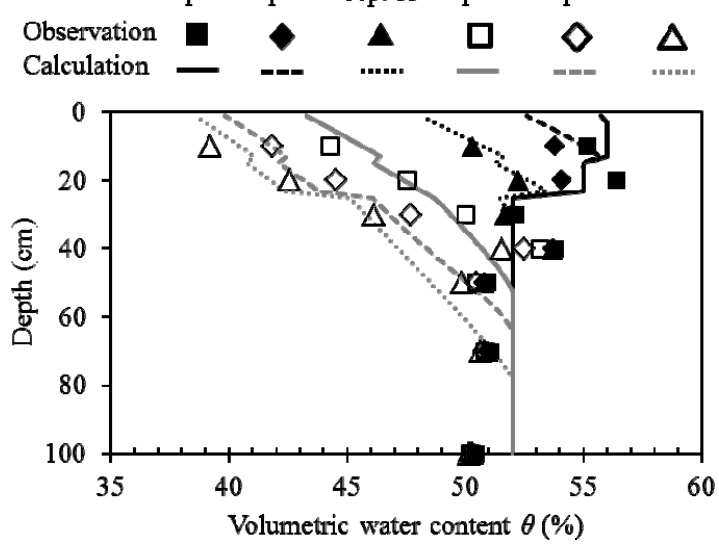

Fig. 16 Comparison of calculated water content with observation results. (a) time series, (b) vertical profiles.

results are summarized as follows:

(1) Soil texture was vertically consistent, and the soil was classified as "silt loam with less sand" to 50 $\mathrm{cm}$. However, bulk density was smaller and porosity was larger in the top $20 \mathrm{~cm}$. Hydraulic conductivity of the upper $20 \mathrm{~cm}$ was estimated as $30 \mathrm{~cm} \cdot \mathrm{d}^{-1}$ from an in si-tu infiltration test. This value was much larger than literature value for similar soils;

(2) Reed rootstocks were classified by appearance as UGS, FOR, and SOR. SOR are long, hair-like roots that penetrate openings among soil grains to absorb groundwater. SOR are concentrated in the upper 20 $\mathrm{cm}$ soil layer and are considered to change the hydraulic characteristics of this layer;

(3) Moisture content in layers high in SOR changes rapidly in response to precipitation and evaporation at 
the ground surface. This suggests that SOR affect vertical water transport and the larger hydrological cycle in reed colonies in wetlands;

(4) The vertical 1-D simulation based on Richard's equation with van Genuchten's function reproduced soil moisture dynamics observed in the field. Thus, Richard's equation, with appropriate calibration, can be used to estimate vertical water transport in surface soils in reed colonies containing large volumes of fine rootstocks.

\section{References}

[1] Maitre, D. C. L., Scott, D. F., and Colvin, C. 1999. "A Review of Information on Interactions between Vegetation and Groundwater." Water S. A. 58 (2): 137-52.

[2] Schilling, K. E., and Kiniry, J. R. 2007. "Estimation of Evapotranspiration by Reed Canary Grass Using Field Observations and Model Simulations." J. Hydrology 337: 356-63.

[3] Lenters, J. D., Cutrell, G. J., and Istanbulluoglu, E. 2011. "Seasonal Energy and Water Balance of a Phragmitesaustralis-dominated Wetland in the Republican River Basin of South-Central Nebraska (USA)." J. Hydrology 408: 19-34.

[4] Zhou, L., and Zhou, G. S. 2009. "Measurement and Modeling of Evapotranspiration over a Reed (Phragmitesaustralis) Marsh in Northeast China." $J$. Hydrology 372: 41-7.

[5] Price, K., Jackson, C. R., and Parker, A. J. 2010. "Variation of Surficial Soil Hydraulic Properties across Land Uses in the Southern Blue Ridge Mountains, North Carolina, USA." J. Hydrology 383: 256-68.

[6] Li, Y. Y., and Shao, M. A. 2006. "Change of Soil Physical Properties under Long-term Natural Vegetation
Restoration in the Loess Plateau of China." J. Arid Environments 64: 77-96.

[7] Štekauerovă, V., and Mikulec, V. 2009. "Variability of Saturated Hydraulic Conductivities in the Agriculturally Cultivated Soils.” Soil \& Water Res. Special 2: 14-21.

[8] Schwartz, R. C., Evett, S. R., and Unger, P. W. 2003. "Soil Hydraulic Properties of Cropland Compared with Reestablished and Native Grassland." Geoderma 116: 47-60.

[9] Sonmez, S., Buyuktas, D., Okturen, F., and Citak, S. 2008. "Assessment of Different Soil to Water Ratios (1:1, $1: 2.5,1: 5)$ in Soil Salinity Studies." Geoderma 144: 361-9.

[10] Van Genuchten, M. Th. 1980. “A Closed-form Equation for Predicting the Hydraulic Conductivity of Unsaturated Soils." Soil Sci. Soc. Am. J. 44: 892-8.

[11] Green, W. H., and Ampt, G. A. 1911. "Studies in Soil Physics, the Flow of Air and Water through Soils." $J$. Agricultural Science 4: 1-24.

[12] Carsel, R. F., and Parrish, R. S. 1988. "Developing Joint Probability Distributions of Soil Water Retention Characteristics." Water Resource. Res. 24 (5): 755-69.

[13] Sentek Sensor Technologies. 2011. "Calibration Manual for Sentek Soil Moisture Sensors." Accessed April 1, 2011. http://www.sentek.com.au.

[14] Paltineanu, I. C., and Starr, J. L. 1997. "Real-time Soil Water Dynamics Using Multisensor Capacitance Probes. Laboratory Calibration." Soil Sci. Soc. Am. J. 61: 1576-85.

[15] Chen, F., and Dudhia, J. 2001. "Coupling an Advanced Land Surface-hydrology Model with the Penn State-NCAR MM5 Modeling System. Part I.” Model Implementation and Sensitivity, Mon. Weather Rev. 129 (4): 569-585.

[16] National Oceanic and Atmospheric Administration. 2012. "Global Vegetation Processing System (GVPS) Green Vegetation Fraction." Accessed Sept 17, 2012. http://www.ospo.noaa.gov/Products/land/gvps/GVF.html. 